\title{
Tissue-engineered trachea from sheep marrow stromal cells with transforming growth factor $\beta 2$ released from biodegradable microspheres in a nude rat recipient
}

\author{
Koji Kojima, MD, $\mathrm{PhD}^{\mathrm{a}}$ \\ Ronald A. Ignotz, $\mathrm{PhD}^{\mathrm{b}}$ \\ Toshihiro Kushibiki, MS ${ }^{\mathrm{c}}$ \\ Kevin W. Tinsley, $\mathrm{MA}^{\mathrm{a}}$ \\ Yasuhiko Tabata, PhD, DMedSci, DPharm ${ }^{\mathrm{c}}$ \\ Charles A. Vacanti, MD
}

See related articles on pages 14 and 124.
From the Laboratory for Tissue Engineering and Regenerative Medicine, Brigham \& Women's Hospital, Harvard Medical School, ${ }^{\text {a }}$ Worcester, Mass, the Center for Tissue Engineering, University of Massachusetts Medical School, ${ }^{\mathrm{b}}$ Boston, Mass, and the Institute for Frontier Medical Sciences, Kyoto University, ${ }^{\mathrm{c}}$ Kyoto, Japan.

Funded by the University of Massachusetts Medical School and Worcester Foundation for Biomedical Research.

Read at the Eighty-third Annual Meeting of The American Association for Thoracic Surgery, Boston, Mass, May 4-7, 2003.

Received for publication May 11, 2003; revisions requested Feb 4, 2004; accepted for publication Feb 26, 2004.

Address for reprints: Koji Kojima, MD, $\mathrm{PhD}$, Laboratory for Tissue Engineering and Regenerative Medicine, Department of Anesthesiology, Brigham and Women's Hospital, 75 Francis St, Thorn 1334, Boston, MA 02115 (E-mail: kojima@zeus.bwh. harvard.edu).

J Thorac Cardiovasc Surg 2004;128:147-53 $0022-5223 / \$ 30.00$

Copyright $\odot 2004$ by The American Association for Thoracic Surgery

doi:10.1016/j.jtcvs.2004.02.038
Objective: The purpose of this study was to evaluate the feasibility of using autologous sheep marrow stromal cells cultured onto polyglycolic acid mesh to develop helical engineered cartilage equivalents for a functional tracheal replacement. We also explored the potential benefit of local delivery of transforming growth factor $\beta 2$ with biodegradable gelatin microspheres.

Methods: Bone marrow was obtained by iliac crest aspiration from 6-month-old sheep and cultured in monolayer for 2 weeks. At confluence, the cells were seeded onto nonwoven polyglycolic acid fiber mesh and cultured in vitro with transforming growth factor $\beta 2$ and insulin-like growth factor 1 for 1 week. Cell-polymer constructs were wrapped around a silicone helical template. Constructs were then coated with microspheres incorporating $0.5 \mu \mathrm{g}$ transforming growth factor $\beta 2$. The cell-polymer-microsphere structures were then implanted into a nude rat. On removal, glycosaminoglycan content and hydroxyproline were analyzed in both native and tissue-engineered trachea. Histologic sections of both native and tissue-engineered trachea were stained with hematoxylin and eosin, safranin-O, and a monoclonal anti-type II collagen antibody.

Results: Cell-polymer constructs with transforming growth factor $\beta 2$ microspheres formed stiff cartilage de novo in the shape of a helix after 6 weeks. Control constructs lacking transforming growth factor $\beta 2$ microspheres appeared to be much stiffer than typical cartilage, with an apparently mineralized matrix. Tissue-engineered trachea was similar to normal trachea. Histologic data showed the presence of mature cartilage. Glycosaminoglycan and hydroxyproline contents were also similar to native cartilage levels.

Conclusions: This study demonstrates the feasibility of engineering tracheas with sheep marrow stromal cells as a cell source. Engineering the tracheal equivalents with supplemental transforming growth factor $\beta 2$ seemed to have a positive effect on retaining a cartilaginous phenotype in the newly forming tissue.

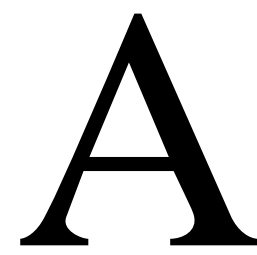

t present it is still not known which cartilage source is the easiest to obtain and which requires the least invasive techniques for harvesting to provide a cellular sample for constructing a tissueengineered trachea (TET). We have observed and published that nasal septum cartilage is a potential site for obtaining an adequate sample for further tissue engineering studies. ${ }^{1,2}$ What is advantageous about hyaline cartilage of the nasal septum is that not only is it very similar to tracheal cartilage but it is also a source for epithelial cells and connective tissues. 

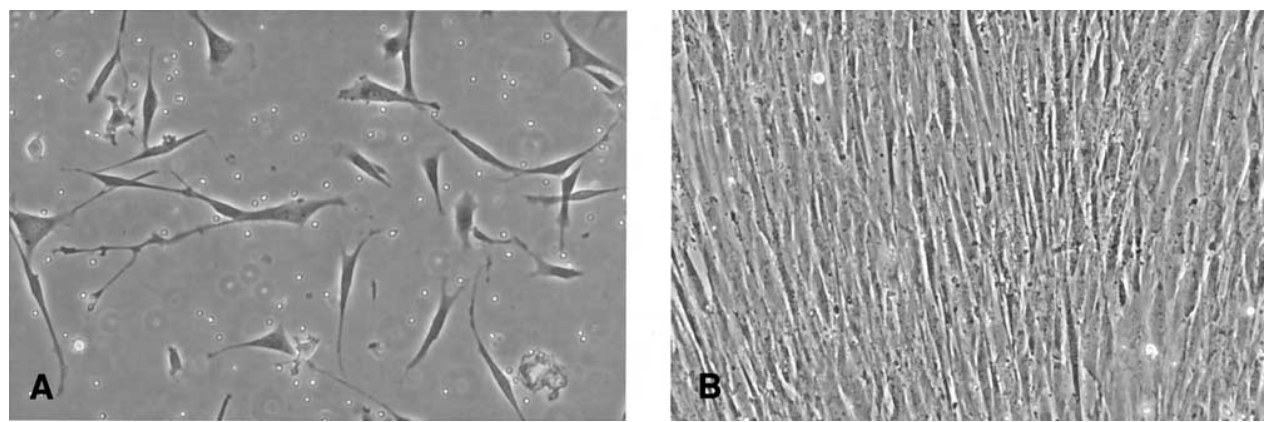

Figure 1. Phase-contrast photomicrograph at $200 \times$ of sheep MSCs in monolayer culture. A, Cells attaching and colonizing surface of culture flask at 4 days. B, Cells continued to proliferate, and after 14 days initial culture became confluent.

The obvious benefit is that from the same small nasal septum biopsy specimen one is able to culture out three different cell types, each necessary for in vitro 3-dimensional tissue construction. However, cartilage harvested from nasal tissue should not be considered a universal source for all cases where tissue engineering could be beneficial, for example in patients with smoke inhalation and in children.

Other cellular sources that have the potential use in tissue-engineering studies need to be investigated. Recently it has been demonstrated that stem cells may be a potential source that can be exploited by tissue engineers. ${ }^{3}$ For engineering bone and cartilage, our laboratory believes that marrow stromal cells (MSCs) hold the greatest therapeutic potential. An additional advantage of using stromal stem cells is that obtaining them is less invasive than removing a sample of nasal cartilage.

This study was designed to evaluate the feasibility of using autologous sheep MSCs cultured onto a polyglycolic acid (PGA) mesh to develop a helically engineered cartilage equivalent of a functional trachea. Transforming growth factor (TGF) $\beta$ has been shown to play a major role in cartilage development, and studies have demonstrated that TGF- $\beta 2$ helps support chondrogenesis in developing 3-dimensional tissue constructs. We therefore explored the potential benefits of local delivery of TGF- $\beta 2$ to cells with biodegradable microspheres. We were able to locally deliver TGF- $\beta 2$ by coupling its release to the degradation of a biodegradable hydrogel prepared by cross-linking acidic gelatin with glutaraldehyde. This gelatin hydrogel incorporating TGF- $\beta 2$ effectively promoted cartilage regeneration in vivo.

\section{Materials and Methods}

\section{Preparation of Gelatin Microspheres Incorporating}

TGF- $\beta 2$

Gelatin with an isoelectric point of 5.0, prepared through alkaline procedure of bovine bone, was kindly supplied from Nitta Gelatin
Inc (Osaka, Japan). It is named "acid gelatin" because of its low isoelectric point. Gelatin microspheres were prepared by chemical cross-linking of gelatin in a water-in-oil emulsion state, as described previously. ${ }^{4}$ Briefly, aqueous solution of $10 \%$ by weight gelatin $(10 \mathrm{~mL})$ was preheated at $40^{\circ} \mathrm{C}$ and then added dropwise into $375 \mathrm{~mL}$ olive oil preheated at $40^{\circ} \mathrm{C}$, while an impeller stirring at $420 \mathrm{rpm}$ was performed for 10 minutes to yield a water-in-oil emulsion. The emulsion temperature was decreased to $4^{\circ} \mathrm{C}$, followed by further stirring for 30 minutes for the natural gelation of gelatin aqueous solution. Cold acetone $(100 \mathrm{~mL})$ was added to the emulsion, and stirring was continued for 10 minutes. The resulting microspheres were washed three times with cold acetone, collected by centrifugation ( $5000 \mathrm{rpm}, 4^{\circ} \mathrm{C}, 5$ minutes), fractionated in size by sieves with apertures of 70 and $100 \mu \mathrm{m}$, and air-dried at $4^{\circ} \mathrm{C}$. The average diameter of the microspheres used was $75 \mu \mathrm{m}$. The non-cross-linked and dried gelatin microspheres $(20 \mathrm{mg})$ were placed in $20 \mathrm{~mL}$ of $0.1 \%$ by weight polysorbate 80 aqueous solution containing $100 \mu \mathrm{L}$ of $25 \%$ by weight glutaraldehyde solution and stirred at $4^{\circ} \mathrm{C}$ for 24 hours to allow the gelatin to cross-link. After washing by centrifugation $\left(5000 \mathrm{rpm}, 4^{\circ} \mathrm{C}, 5\right.$ minutes) with double-distilled water, the microspheres were agitated in $20 \mathrm{~mL}$ of $100-\mathrm{mmol} / \mathrm{L}$ aqueous glycine solution at room temperature for 1 hour to block the residual aldehyde groups of unreacted glutaraldehyde. The resulting microspheres were washed three times with double-distilled water by centrifugation and freeze-dried. To impregnate TGF- $\beta 2$ into gelatin microspheres, $20 \mu \mathrm{L}$ of $100-\mathrm{mmol} / \mathrm{L}$ phosphate-buffered saline solution (pH 7.4) containing $20 \mu \mathrm{g}$ TGF- $\beta 2$ was dropped onto $2 \mathrm{mg}$ of the freeze-dried gelatin microspheres and left overnight at $4^{\circ} \mathrm{C}$. The TGF- $\beta 2$ was completely incorporated into gelatin microspheres by this impregnation procedure because the volume of TGF- $\beta 2$ solution was small enough compared with that theoretically incorporated into the microspheres.

\section{Cell Isolation and Culture}

Sheep bone marrow cells were obtained by iliac crest aspiration from 6 month-old sheep. The aspirate were cultured in Dulbecco modified Eagle medium (GIBCO; Life Technologies, Inc, Rockville, Md) containing 10\% fetal calf serum (GIBCO; Life Technologies) with $292-\mu \mathrm{g} / \mathrm{mL}$ L-glutamine, $10,000-\mathrm{U} / \mathrm{mL}$ penicillin $\mathrm{G}, 10,000-\mathrm{U} / \mathrm{mL}$ streptomycin sulfate, and $25 \mu \mathrm{g} / \mathrm{mL}$ amphotericin 

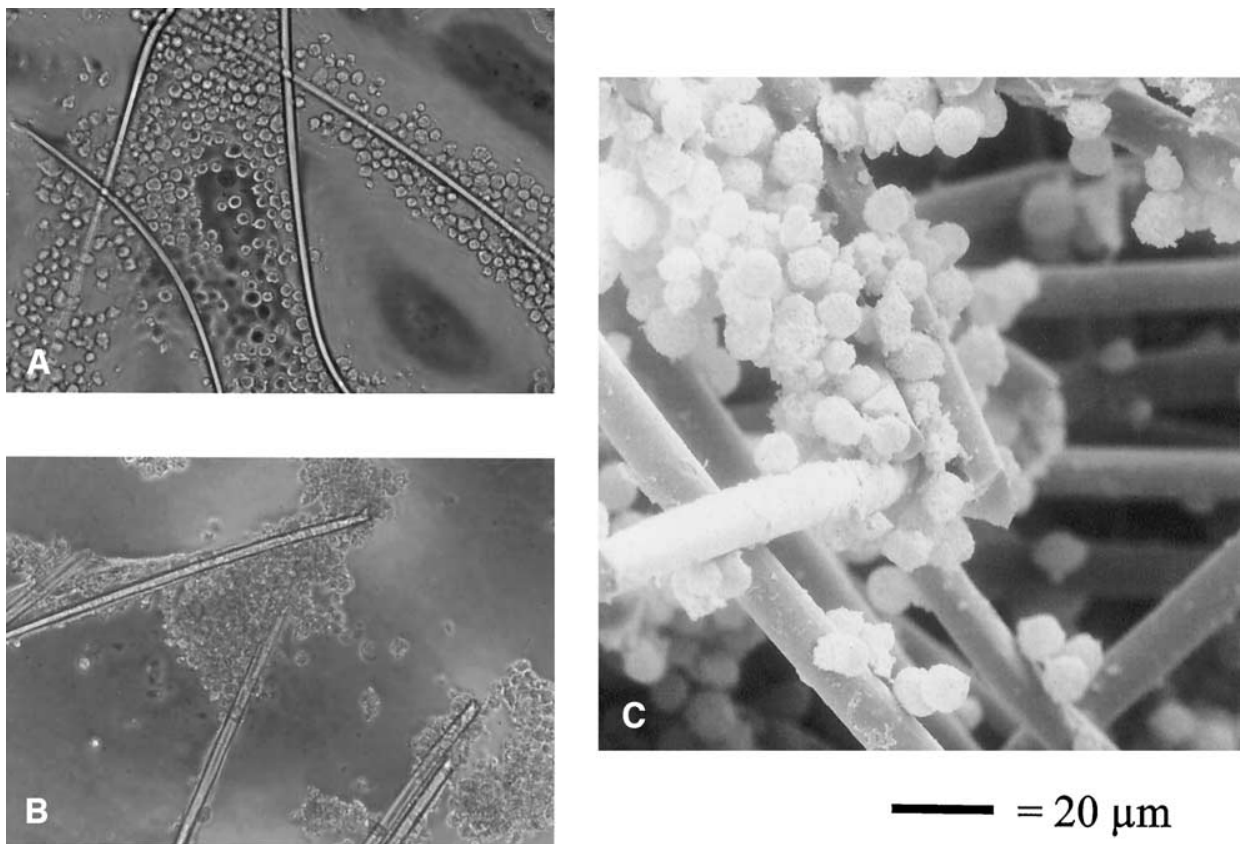

Figure 2. A, Cells attaching to PGA on day 0. B, Growth of cells and matrix on day 7. C, Electron microscopy shows cells firmly attached to PGA by day 4.

B. Culture medium was changed every 2 days (Figure $1, A$ ). After 2 weeks, a confluent monolayer was obtained (Figure 1, B). Cells were harvested by digestion with $0.05 \%$ trypsin-ethylenediaminetetraacetic acid (GIBCO; Life Technologies). The isolated cells were counted with a hemocytometer, and their viability was determined with use of the trypan-blue (Sigma-Aldrich, Irvine, Calif) exclusion method.

\section{Cell Seeding and Implantation}

Cell suspensions were concentrated at $50 \times 10^{6}$ cells $/ \mathrm{mL}$ and seeded on a $100 \times 10 \times 2$-mm nonwoven mesh of PGA fibers (Davis \& Geck, Danbury, Conn; Figure 2, A). The serum-containing media was then replaced with Dulbecco modified Eagle medium with ITS + Premix (Becton Dickinson Microbiology Systems, Sparks, Md), L-ascorbic acid 2-phosphate (Sigma, St Louis, Mo), 10-nmol/L dexamethasone, TGF- $\beta 2$ (10 ng/mL) (PeproTech, Inc, Rocky Hill, NJ), and insulin-like growth factor $1(25 \mathrm{ng} / \mathrm{mL})$ (PeproTech). The cell-seeded mesh samples were continuously cultured for 1 week in vitro (Figure 2, $B$ and $C$ ). Please note the initial cell seeding number needs to be at least $50 \times 10^{6}$ cells $/ \mathrm{mL}$, because when we change the medium every day unattached cells spill out of the PGA mesh and are lost. This is the why we seed the PGA mesh at such a high concentration. The structures were then placed in the grooves of a 20 -mm diameter $\times 50$-mm long helical template made with a Silastic ERTV mold-making kit (Dow Corning, Midland, Mich). Cell-polymer samples were coated with gelatin microspheres with $(\mathrm{n}=6)$ or without $(\mathrm{n}=6)$ TGF- $\beta 2$ (Figure 3,A). The composite structures were implanted subcutaneously in athymic rats and harvested after 6 weeks (Figure 3, B). The implants were analyzed histologically and biochemically.
Tissue was assayed for cartilage-specific extracellular matrix components, including proteoglycans and collagen. All animals received humane care in compliance with the "Principles of Laboratory Animals Care" formulated by the National Society for Medical Research and the "Guide for the Care and Use of Laboratory Animals" (http://www.nap.edu/catalog/5140.html). All animal procedures complied with the guidelines provided by the institutional animal care and use committee of the University of Massachusetts Medical School.

\section{Histologic Examinations}

The specimens for histology were fixed in 10\% phosphate-buffered formalin and embedded in paraffin and sectioned. Sections were stained with hematoxylin, eosin, safranin-O and a mouse monoclonal anti-type II collagen antibody.

\section{Biochemical Analysis}

Samples were digested by the addition of $1.0 \mathrm{~mL}$ of $100-\mathrm{mmol} / \mathrm{L}$ sodium phosphate, $10-\mathrm{mmol} / \mathrm{L}$ sodium ethylenediaminetetraacetic acid, and 10-mmol/L cysteine hydrochloride (Sigma). The specimens were incubated in the $60^{\circ} \mathrm{C}$ water bath for 24 hours. ${ }^{5}$

Glycosaminoglycan content. The glycosaminoglycan content of tissue digested was quantified according to a previously described method. ${ }^{6}$ Briefly, $50 \mu \mathrm{L}$ papain digest was added to $2 \mathrm{~mL}$ 1,9-dimethylmethylene blue dye at $\mathrm{pH} 3.0$, with absorbencies detected at $490 \mathrm{~nm}$ with a spectrophotometer immediately after the addition of the dye. Glycosaminoglycan contents of the specimens were determined with chondroitin 6-sulfate from shark cartilage (Sigma) as a standard. All samples and standards were analyzed in duplicate. 

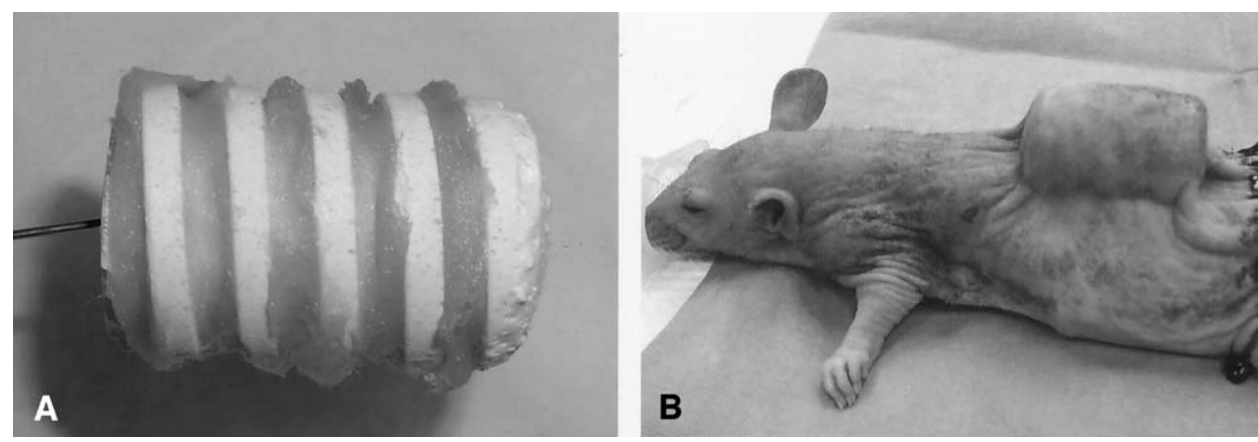

Figure 3. A, Cell-seeded matrix was placed in grooves of helical templates fabricated with silicone mold-making kit. B, Constructs coated with gelatin microspheres incorporating TGF- $\beta 2$ were implanted into subcutaneous pockets on nude rats.

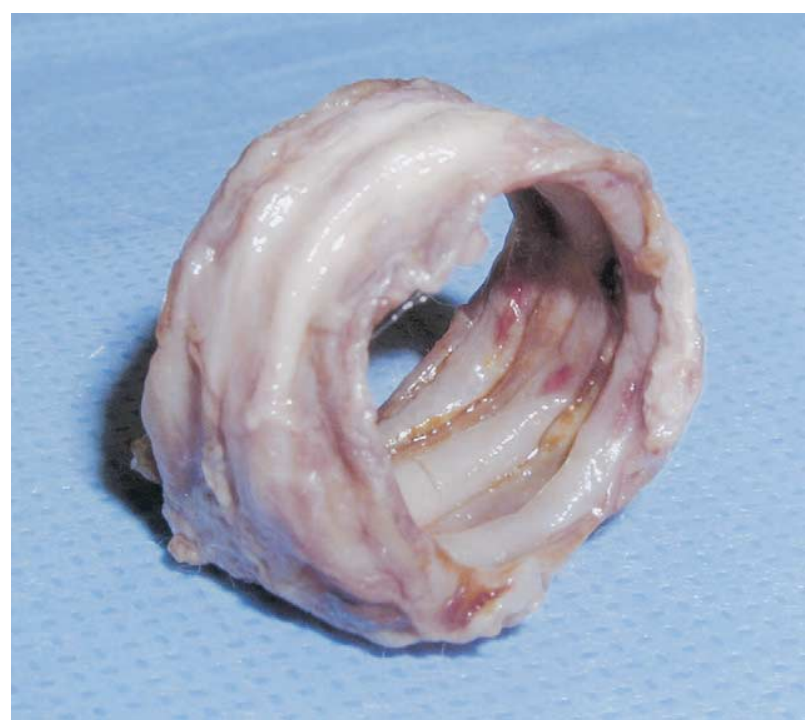

Figure 4. TET from nude rat at 6 weeks after implantation.

Hydroxyproline content. The chloramine $\mathrm{T}$ method was used for the hydroxyproline quantification ${ }^{7}$. Briefly, the papain digests were hydrolyzed with equal volumes of $6 \mathrm{~N}$ hydrochloric acid at $115^{\circ} \mathrm{C}$ for 16 to 24 hours in screw cap glass tubes. Contents of each tube were washed out and transferred into a borosilicate $12 \times$ $75-\mathrm{mm}$ glass tube and dried for 5 hours. Chloramine T hydrate (98\%; Sigma) and p-dimethylaminobenzaldehyde (Ehrlich reagent; Sigma) were added to hydrolyzed specimens, and absorbencies were detected at $560 \mathrm{~nm}$ with a spectrophotometer immediately after the addition of the dye. Collagen content in experimental samples were determined with hydroxyproline standard from Sigma.

\section{Results}

The tissue appearance of specimens prepared with gelatin microspheres without TGF- $\beta 2$ showed fibrous remnants of PGA. However, the tissue appearance of specimens pre- pared with gelatin microspheres incorporating TGF- $\beta 2$ included neovascularization on the surface of engineered cartilage and what appeared to be cartilage.

\section{Gross Morphology}

The gross appearance of the TET was solid and shiny white with a cartilaginous circular helix. The TET showed great similarity native trachea. In addition, these TETs were stiff to the touch yet flexible, similar to native cartilage (Figure $4)$.

\section{Histology}

On histologic examination, the engineered surface was found to be smooth, and formation of cartilage was evident. Hematoxylin and eosin and safranin-O stains demonstrated hyaline cartilage closely resembling that of native tracheal cartilage with similar overall morphologic characteristics (Figure 5, A-D). Staining for type II collagen was strongly positive in both native and engineered cartilage (Figure 5, $E$ and $F$ ).

\section{Biochemical Assay}

Six samples of TET and native trachea were analyzed for proteoglycan and collagen contents. Proteoglycan content of the TET was $49.57 \pm 6.81 \mu \mathrm{g} / \mathrm{mg}$, and that in the native tracheal cartilage was $63.05 \pm 7.3 \mu \mathrm{g} / \mathrm{mg}$. Proteoglycan content of the TET was similar to that in native trachea (Figure 6, A). The collagen content of the TET was $0.35 \pm$ $0.37 \mu \mathrm{g} / \mathrm{mg}$, and that in native tracheal cartilage was $0.49 \pm$ $2.43 \mu \mathrm{g} / \mathrm{mg}$. The collagen content of the TET was similar to that in native trachea (Figure 6, B). There were no statistically significant differences in glycosaminoglycan and hydroxyproline when native and engineered samples were compared $(P>.50)$.

\section{Discussion}

This study shows the feasibility of engineering trachea in vitro with sheep MSCs as a cell source. In addition to simple 

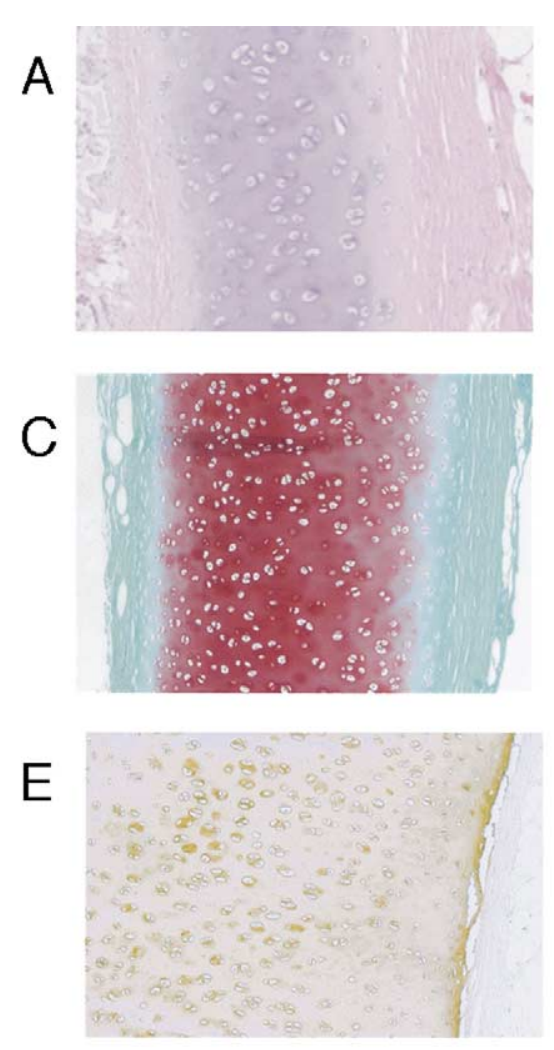
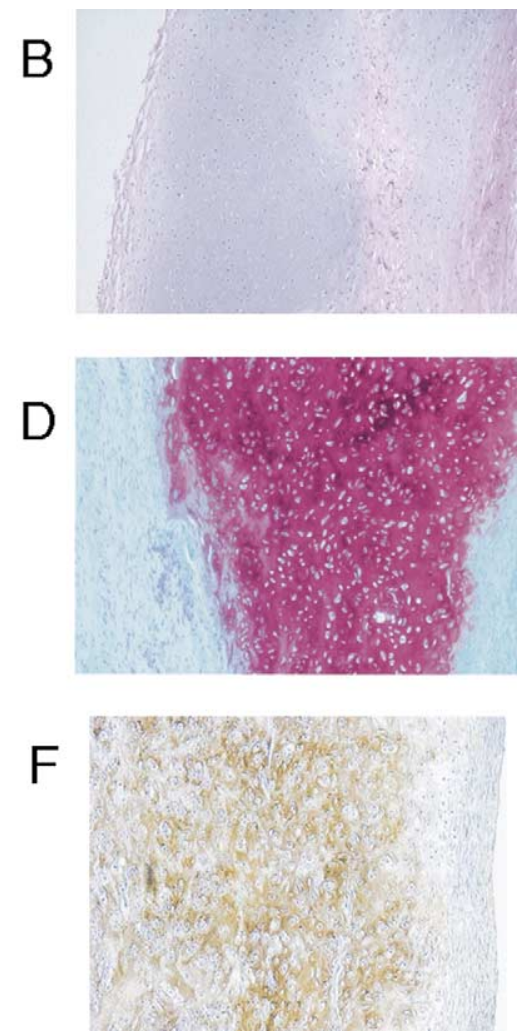

Figure 5. Hematoxylin and eosin staining (magnification $100 \times$ ) of TET (A) and native trachea (B). Safranin-0 staining was deeply positive, indicative of abundant proteoglycan production, in both TET (C) and native trachea (D). Staining for type collagen II was strongly positive in extensive extracellular matrix of engineered (E) and native $(F)$ sections.

efficiency, the use of MSCs also has a clinical advantage. Harvesting bone marrow under local anesthesia obviates the risk and expense associated with general anesthesia. For critically injured patients, a major population that may need tracheal replacement surgery, this is particularly advantageous. Because of MSCs' unique ability to form at least five types of connective tissues, including bone and cartilage ${ }^{8}$, it is possible to create cartilage with a less invasive aspiration technique. In combination with in vitro tissue culturing, it is possible to obtain large numbers of each of the cell types, further sparing the patient from multiple procedures.

For this study, MSCs were allowed to reach confluence, in approximately 2 weeks, before they were treated with any growth factors that would result in the differentiation of the MSCs into connective tissues. The growth factors TGF- $\beta 1$, TGF- $\beta 2$, and TGF- $\beta 3$ have the ability to induce chondrogenic differentiation in chondrocyte and mesenchymal stem cells; however, not with equal effect. Barry and colleagues ${ }^{9}$ have reported that TGF- $\beta 2$ and TGF- $\beta 3$ promote chondrogenesis more potently than does TGF- $\beta 1$, causing a 2 -fold greater accumulation of glycosaminoglycan and a more extensive deposition of type II collagen than if cells are treated with TGF- $\beta 1$. Therefore after 2 weeks the cells were seeded onto a PGA mesh and cultured with TGF- $\beta 2$ and insulin-like growth factor 1 for an additional week to induce differentiation. The cells were also cultured with insulinlike growth factor 1 because it helps to regulate cellular proliferation as well as increasing extra cellular matrix synthesis and metabolism, processes crucial for cartilage regulation.

In gross morphologic appearance, the TET was very similar to native tracheal cartilage in that it had excellent rigidity and patency. We observed significant angiogenesis on the surface of engineered cartilage, providing the necessary vascular supply needed by the new tissue. Cartilage differentiation was dependent on TGF- $\beta 2$, as demonstrated by the fact that the samples treated with biodegradable, gelatin microspheres lacking TGF- $\beta 2$ group did not differentiate into cartilage effectively. However, microspheres containing TGF- $\beta 2$ released through an extended period induced significant chondrogenic differentiation. This is in agreement with previously published reports demonstrating that TGF- $\beta$ is in part responsible for the formation of fibrous scar tissue. ${ }^{10}$ Although we saw extensive angiogenesis and tissue formation, we could not definitively state that the tissue 

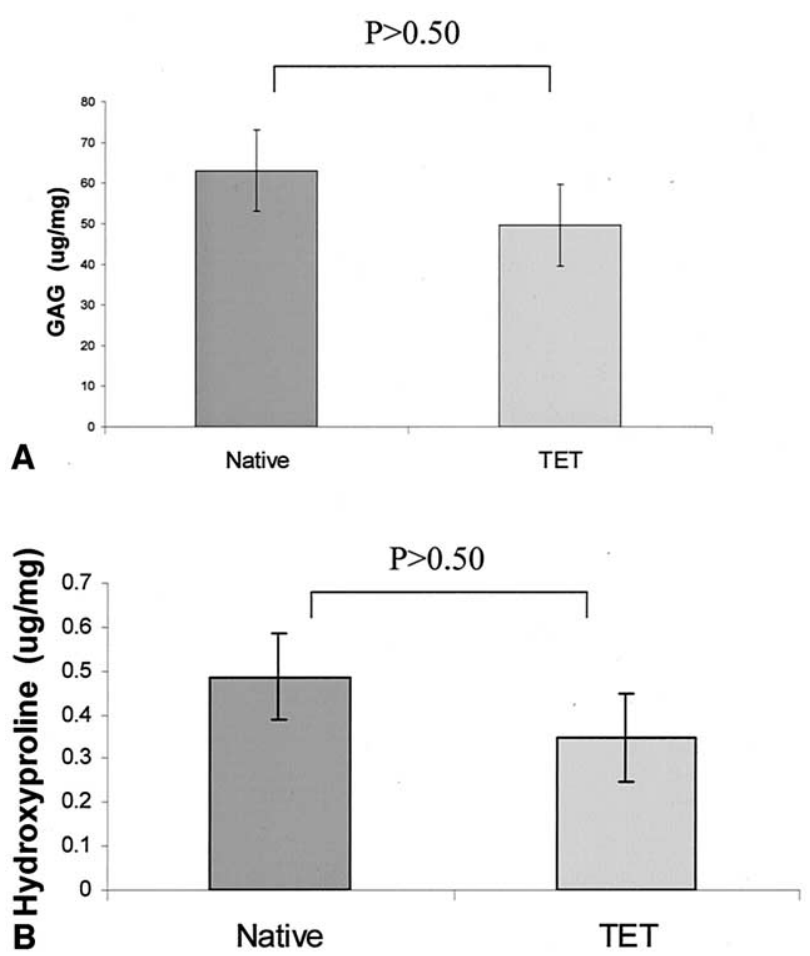

Figure 6. A, Glycosaminoglycan (GAG) contents of native trachea and TET. B, Hydroxyproline contents of native trachea and TET. Bar heights represent mean of 6 observations; error bars represent SD. Data were not statistically different according to 1-way analysis of variance.

between the cartilage rings was rat tissue as opposed to sheep tissue. However, we feel confident that the tissue between the rings was rat tissue because sheep MSCs were seeded into circular grooves of the template only, not spread across the entire surface of the template. Clinical treatment strategies in the future would use the patient's own cells, thus eliminating any potential immunologic reactions. For this reason we did not feel it was necessary to differentiate rat tissue from sheep tissue in this study. We conclude that the controlled release of TGF- $\beta 2$ not only enhanced chondrogenesis but also induced connective tissue growth, resulting in neovascularization.

A histologic evaluation of the TET 6 weeks after implantation revealed mature hyaline cartilage with evenly distributed lacunae that contained single chondrocytes. Safranin-O staining was deeply positive, indicative of abundant proteoglycan production in the matrix. There was evidence of chondrogenic differentiation, demonstrated by the positive staining for type II collagen in the extracellular matrix of the engineered cartilage. Biochemical analysis comparing the proteoglycan and collagen contents in TET and native tracheal cartilage demonstrated that the proteoglycan content of the TET was
$49.57 \pm 6.81 \mu \mathrm{g} / \mathrm{mg}$, approximately $78 \%$ of that of native tracheal cartilage $(63.05 \pm 7.3 \mu \mathrm{g} / \mathrm{mg})$. The collagen content of the TET was $0.35 \pm 0.37 \mu \mathrm{g} / \mathrm{mg}, 71 \%$ of that of native tracheal cartilage $(0.49 \pm 2.43 \mu \mathrm{g} / \mathrm{mg})$. These results clearly demonstrate that TET derived from MSCs is similar to native tissue, and we are optimistic about the potential for generating human trachea in vivo by culturing sheep MSCs onto PGA fibers and using biodegradable microspheres to deliver locally TGF- $\beta 2$.

We thank Gregory Hendricks for performing the scanning electron microscopy. We also thank Michelle Maynard for her expert technical assistance and preparation of materials for these experiments.

\section{References}

1. Kojima K, Bonassar LJ, Roy AK, Mizuno H, Cortiella J, Vacanti CA. A composite tissue-engineered trachea using sheep nasal chondrocyte and epithelial cells. FASEB J. 2003;17:823-8.

2. Kojima K, Bonassar LJ, Roy AK, Vacanti CA, Cortiella J. Autologous tissue-engineered trachea with sheep nasal chondrocytes. J Thorac Cardiovasc Surg. 2002;123:1177-84.

3. Bianco P, Robey PG. Stem cells in tissue engineering. Nature. 2001; 414:118-21.

4. Tabata Y, Hijikata S, Muniruzzaman M, Ikada Y. Neovascularization effect of biodegradable gelatin microspheres incorporating basic fibroblast growth factor. J Biomater Sci Polym Ed. 1999;10:79-94.

5. Kim YJ, Sah RL, Doong JY, Grodzinsky AJ. Fluorometric assay of DNA in cartilage explants using Hoechst 33258. Anal Biochem. 1988; 174:168-76.

6. Farndale RW, Buttle DJ, Barrett AJ. Improved quantitation and discrimination of sulphated glycosaminoglycans by use of dimethylmethylene blue. Biochim Biophys Acta. 1986;883:173-7.

7. Stegemann H, Stalder K. Determination of hydroxyproline. Clin Chim Acta. 1967;18:267-73.

8. Kuznetsov SA, Friedenstein AJ, Robey PG. Factors required for bone marrow stromal fibroblast colony formation in vitro. $\mathrm{Br} \mathrm{J}$ Haematol. 1997;97:561-70.

9. Barry F, Boynton RE, Liu B, Murphy JM. Chondrogenic differentiation of mesenchymal stem cells from bone marrow: differentiationdependent gene expression of matrix components. Exp Cell Res. 2001; 268:189-200.

10. Shah M, Foreman DM, Ferguson MW. Neutralisation of TGF-beta 1 and TGF-beta 2 or exogenous addition of TGF-beta 3 to cutaneous rat wounds reduces scarring. J Cell Sci. 1995;108(Pt 3):985-1002.

\section{Discussion}

Dr Paolo Macchiarini (Hannover, Germany). Tracheal transplantation has been the subject of ongoing research for more than 40 years, without success. The concept of TET is the most recent, and maybe the "sexiest," idea that has been generated in recent years. However, there are a few points that everybody should know to understand the process and rationale behind tracheal transplantation. I advise a look at the review by Grillo in The Annals of Thoracic Surgery (2002;73:1995-2004) a few months ago. I saw him yesterday. "You know why I did this review on tracheal transplantation," he said simply. "Well, I would like that the youngest that are doing this research have a look, so that the killing of small and large animals should be stopped."

There are a few concerns and a few questions. My concern is, could you, for instance, isolate the given cells only from the peripheral blood and not from a bone marrow biopsy sample? I ask 
because one of the indications you could eventually have is a patient with cancer.

Dr Kojima. I agree. I would not suggest this tissue-engineering technique in a patient with cancer. I would use it for benign polychondritis or some other injury.

Dr Macchiarini. The second question is, I saw in your slides a tube just made from cartilage and nothing else. I understand that the trachea is an organ with its own vascular pedicle, its own function. This is not only the contracted function but an immunologic and a mechanical function. How do you deal with ischemia if one segment is longer than $6 \mathrm{~cm}$, which is what we really need in clinical practice?

Dr Kojima. I agree, vascularization is the most important factor. So when we move to autologous model, which means we harvest sheep MSCs and then implant them into the same sheep under the sternocleidomastoid muscle, maybe we will want to use both TFG- $\beta 2$ and fibroblast growth factor, because TGF- $\beta 2$ both induces cartilaginous differentiation and forms fibrous tissue. Fibroblast growth factor also induces vascularization. And we have data demonstrating that both TGF- $\beta 2$ and fibroblast growth factor can be released from the gelatin microspheres. Also, for cartilage to grow it may be necessary to have perichondrium present to provide nutrients to the growing cartilage. So it might be necessary to consider how to differentiate perichondrium from other MSCs. I believe that we will be able to make a functional trachea, but I am not sure about longer than $6 \mathrm{~cm}$.

With respect to epithelialization, we think that if we use less than $5 \mathrm{~cm}$ of TET, which is 8 to 10 tracheal rings, we don't need epithelialization. We have data demonstrating that epithelialization can be grown and expanded from both native sides. Even if epithelialization cannot grow, it doesn't matter, because with less than a 5-cm defect, the sheep can skip this lesion with a light cough. 